\title{
Punched-out erosions in sacroiliac joints
}

\author{
Gözde Kübra Yardımcı ${ }^{1}$ (D) Üstün Aydıngöz ${ }^{2}$. Umut Kalyoncu ${ }^{1}$
}

Received: 16 January 2021 / Revised: 11 March 2021 / Accepted: 15 March 2021 / Published online: 23 March 2021

(C) International League of Associations for Rheumatology (ILAR) 2021

\section{Presentation}

A 64-year-old woman was admitted to the rheumatology department with intense joint pain of the extremities and lower back pain. She had a history of chronic kidney disease attributed to type 2 diabetes mellitus and hyperuricemia but no history of spondyloarthritis ( $\mathrm{SpA})$ or SpA features. The patient had been diagnosed as having gout for 4 years, with podagra, and was started allopurinol with colchicine. However, she did not adhere to the treatment protocol and was using corticosteroids irregularly. Her physical examination revealed bilateral symmetric polyarthritis of the hands and feet and tophi on the extensor surfaces of elbows and over bilateral helices. The patient's bilateral hip flexion and rotation were limited and extremely painful. Investigations showed elevated $\mathrm{Cr}$ at $5.3 \mathrm{mg} / \mathrm{dL}$, uric acid at $13.2 \mathrm{mg} / \mathrm{dL}$, and C-reactive protein at $6 \mathrm{mg} / \mathrm{L}$. There were suspicious erosions on the X-ray of the pelvis. Computed tomography (CT) of hip and sacroiliac joints was performed. Sacroiliac joint CT revealed well-defined punch-out erosions surrounded by sclerotic margins, with overhanging edges in the axial (arrows in $\mathrm{b}$ and $\mathrm{c}$ ) and coronal (arrows in d) planes. The patient was diagnosed with gout on the basis of ultrasonographic and clinical findings. Colchicine and allopurinol were restarted, along with dietary recommendations. At the 3-month follow-up visit, the arthritis in the hands and feet of the patient had almost completely disappeared, but the hip pain persisted.

\section{Discussion}

Gout initially presents with episodes of mono-arthritis on the lower extremity; with time intervals in between attacks becoming shorter, the upper limbs also get involved, leading to a chronic polyarticular pattern [1]. Although gout typically affects the peripheral joints, axial involvement occasionally may be seen in the long term and in poorly controlled patients [2].

Crystalline-induced acute sacroiliitis is one of the reasons of acute sacroiliac pain and has specific CT findings, so axial imaging should be performed in cases of clinical suspicion [3, 4]. These eccentric erosions, also known as "rat bite" erosions, are rare findings of gout but lead to significant pain, joint damage, and disability (Fig. 1).

Umut Kalyoncu

umut.kalyoncu@yahoo.com

1 Division of Rheumatology, Department of Internal Medicine, Hacettepe University Faculty of Medicine, Ankara, Turkey

2 Department of Radiology, Hacettepe University Faculty of Medicine, Ankara, Turkey 
Fig. 1 X-Ray of the sacroiliac joints and pelvis are showing sclerosis on the sacroiliac joint and suspicious erosions (a). Sacroiliac joint CT reveals welldefined punch-out erosions surrounded by sclerotic margins, with overhanging edges in the axial (arrows in (b) and (c)) and coronal (arrows in $(\mathbf{d}))$ planes

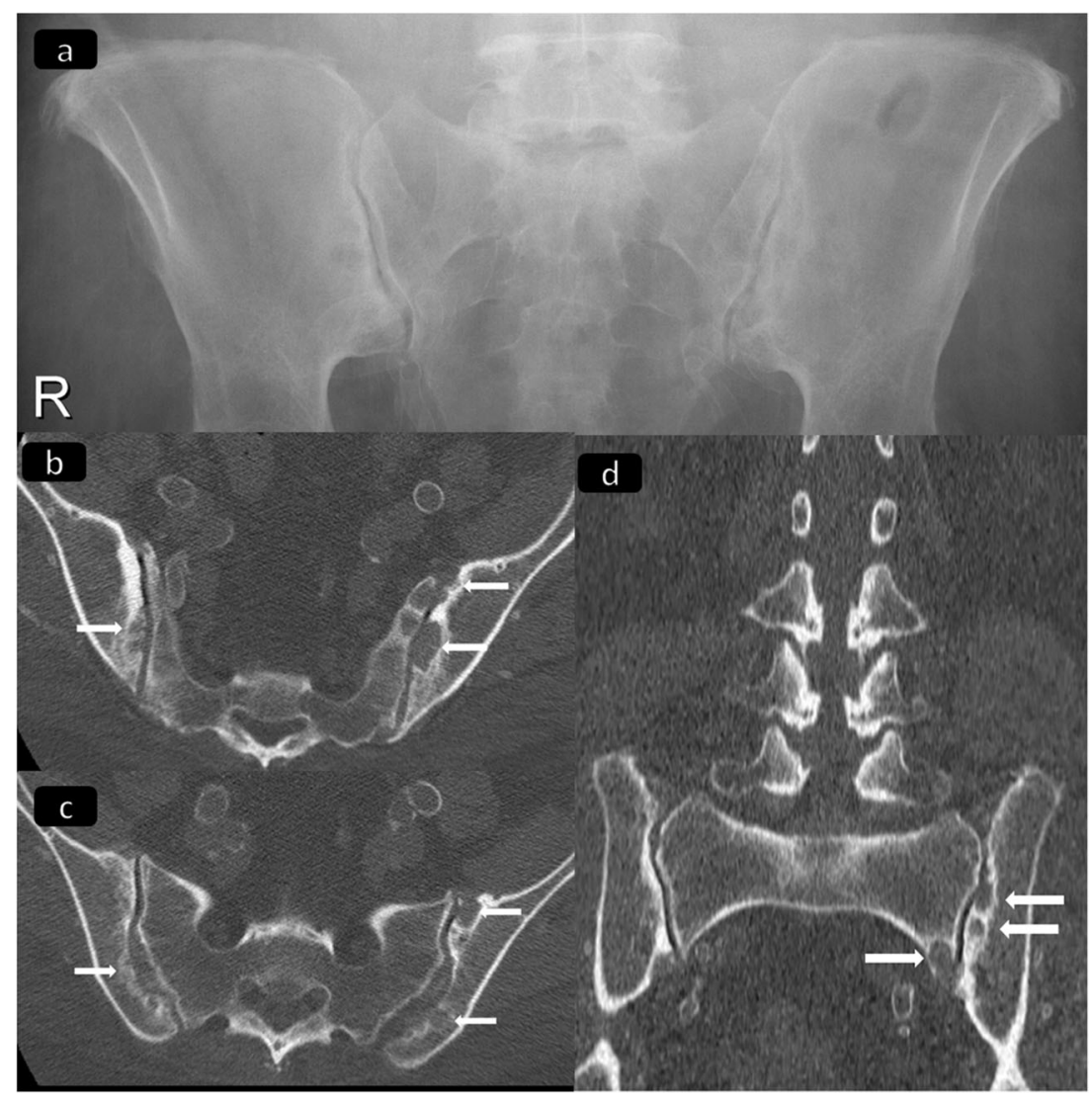

Authors' contributions All authors contributed equally.

Data availability Data available on request.

\section{Declarations}

Ethics approval Written consent was obtained from the patient for this case study and related clinical images.

Conflict of interest UK: Received consultancy fees and/or speaker fees from Abbvie, Amgen, Janssen, Novartis, Pfizer, Roche, and UCB Pharma. Other authors have no conflict of interest.

\section{References}

1. Dalbeth N, Merriman TR, Stamp LK (2016) Gout. Lancet 388: 2039-2052. https://doi.org/10.1016/S0140-6736(16)00346-9

2. Zhang T, Yang F, Li J, Pan Z (2019) Gout of the axial joint-A patient level systemic review. Semin Arthritis Rheum 48(4):649-657. https://doi.org/10.1016/j.semarthrit.2018.04.006

3. Slobodin G, Rimar D, Boulman N, Kaly L, Rozenbaum M, Rosner I et al (2016) Acute sacroiliitis. Clin Rheumatol 35(4):851-856. https://doi.org/10.1007/s10067-016-3200-6

4. Panwar J, Sandhya P, Kandagaddala M, Nair A, Jeyaseelan V, Danda D (2018) Utility of CT imaging in differentiating sacroiliitis associated with spondyloarthritis from gouty sacroiliitis: a retrospective study. Clin Rheumatol 37(3):779-788. https://doi.org/10.1007/ s10067-017-3865-5

Publisher's note Springer Nature remains neutral with regard to jurisdictional claims in published maps and institutional affiliations. 